\title{
The association of kidney function and cognitive decline in older patients at risk of cardiovascular disease: a longitudinal data analysis
}

Laurien E. Zijlstra ${ }^{1 *}$, Stella Trompet ${ }^{1,2}$, Simon P. Mooijaart ${ }^{2}$, Marjolijn van Buren ${ }^{3,4}$, Naveed Sattar ${ }^{5}$, David J. Stott ${ }^{6}$ and J. Wouter Jukema ${ }^{1}$

\begin{abstract}
Background: Chronic kidney disease (CKD) has been identified as a significant direct marker for cognitive decline, but controversy exists regarding the magnitude of the association of kidney function with cognitive decline across the different CKD stages. Therefore, the aim of this study was to investigate the association of kidney function with cognitive decline in older patients at high risk of cardiovascular disease, using data from the PROspective Study of Pravastatin in the Elderly at Risk (PROSPER).

Methods: Data of 5796 patients of PROSPER were used. Strata were made according to clinical stages of CKD based on estimated glomerular filtration rate; $<30 \mathrm{ml} / \mathrm{min} / 1.73 \mathrm{~m}^{2}$ (stage 4), 30-45 ml/min/1.73 $\mathrm{m}^{2}$ (stage 3b), 45-60 $\mathrm{ml} / \mathrm{min} / 1.73 \mathrm{~m}^{2}$ (stage 3a) and $\geq 60 \mathrm{ml} / \mathrm{min} / 1.73 \mathrm{~m}^{2}$ (stage 1-2). Cognitive function and functional status was assessed at six different time points and means were compared at baseline and over time, adjusted for multiple prespecified variables. Stratified analyses for history of vascular disease were executed.

Results: Mean age was 75.3 years and $48.3 \%$ participants were male. Mean follow-up was 3.2 years. For all cognitive function tests CKD stage 4 compared to the other stages had the worst outcome at baseline and a trend for faster cognitive decline over time. When comparing stage 4 versus stage $1-2$ over time the estimates $(95 \% \mathrm{Cl})$ were 2.23 $(0.60-3.85 ; p=0.009)$ for the Stroop-Colour-Word test, $-0.33(-0.66-0.001 ; p=0.051)$ for the Letter-Digit-Coding test, $0.08(-0.06-0.21 ; p=0.275)$ for the Picture-Word-Learning test with immediate recall and $-0.07(-0.02-0.05$; $p=0.509)$ for delayed recall. This association was most present in patients with a history of vascular disease. No differences were found in functional status.

Conclusion: In older people with vascular burden, only severe kidney disease (CKD stage 4), but not mild to modest kidney disease (CKD stage $3 a$ and b), seem to be associated with cognitive impairment at baseline and cognitive decline over time. The association of severe kidney failure with cognitive impairment and decline over time was more outspoken in patients with a history of vascular disease, possibly due to a higher probability of polyvascular damage, in both kidney and brain, in patients with proven cardiovascular disease.
\end{abstract}

Keywords: Cognitive function, Chronic kidney disease, Vascular disease

\footnotetext{
* Correspondence: I.e.zijlstra@lumc.nl

'Department of Cardiology, Leiden University Medical Center, Albinusdreef 2, 2333ZA, Leiden, The Netherlands

Full list of author information is available at the end of the article
}

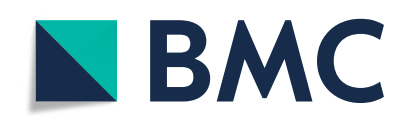

(- The Author(s). 2020 Open Access This article is licensed under a Creative Commons Attribution 4.0 International License, which permits use, sharing, adaptation, distribution and reproduction in any medium or format, as long as you give appropriate credit to the original author(s) and the source, provide a link to the Creative Commons licence, and indicate if changes were made. The images or other third party material in this article are included in the article's Creative Commons licence, unless indicated otherwise in a credit line to the material. If material is not included in the article's Creative Commons licence and your intended use is not permitted by statutory regulation or exceeds the permitted use, you will need to obtain permission directly from the copyright holder. To view a copy of this licence, visit http://creativecommons.org/licenses/by/4.0/. The Creative Commons Public Domain Dedication waiver (http://creativecommons.org/publicdomain/zero/1.0/) applies to the data made available in this article, unless otherwise stated in a credit line to the data. 


\section{Background}

Both chronic kidney disease (CKD) and cognitive impairment are increasingly prevalent with advancing age and partly share a common cause as the kidney and the brain share similar hemodynamic characteristics [1-3]. Both organs are low resistance end organs exposed to high-volume blood flow and therefore predisposed for vascular damage [4]. Next to aging, classical vascular risk factors like hypertension, diabetes and a history of cardiovascular diseases are associated with microvascular damage and small vessel disease in both the kidney and the brain [5-10].

Furthermore, CKD has been identified as a significant marker for cognitive impairment [11, 12]. Although the underlying pathophysiological mechanisms of cognitive dysfunction in CKD remain largely unknown, several candidate mechanisms have been suggested apart from cardiovascular risk factors, which are the same for kidney and brain. In addition, nephrogenic risk factors as uremic toxins, oxidative stress, anaemia, albuminuria and inflammation can lead to cognitive impairment $[10,13]$. Also in end-stage kidney disease determinants related to dialysis, such as intradialytic hypotension or cerebral oedema can lead to cerebral hypoperfusion or neuronal damage $[10,12]$.

The prevalence and magnitude of the association of cognitive impairment across different CKD stages is still subject of debate. Whereas the relationship has been firmly established in patients with end-stage kidney disease, the association of mild to modest impaired kidney function with cognitive function remains questionable [14].

We hypothesized that with decreasing kidney function, cognitive function declines faster over time. Therefore, the aim of this study was to investigate the association of the different stages of CKD and cognitive decline and functional status in a high-risk population of older patients and furthermore, to investigate this association in patients with a history of vascular disease, or patients with only vascular risk factors, using data from the PROspective Study of Pravastatin in the Elderly at Risk (PROSPER).

\section{Methods}

The study population comes from PROSPER, a doubleblind, randomized, placebo-controlled trial, designed to investigate the relationship between statin treatment and the risk of cardiovascular and cerebrovascular events. In summary, 5804 older participants (70-82 years) were enrolled in Ireland, Scotland and The Netherlands. Patients were included if they had a history of, or an increased risk for vascular disease and a baseline cholesterol between $4.0-9.0 \mathrm{mmol} / \mathrm{l}$. A history of vascular disease included stroke, transient ischemic attack, myocardial infarction, arterial surgery, or amputation for vascular disease less than 6 months before study entry. Increased risk for vascular disease included current smoking, hypertension, known diabetes mellitus or fasting blood glucose levels over $7 \mathrm{mmol} / \mathrm{L}$. Mean follow-up was 3.2 years. Detailed description of this population, including all in- and exclusion criteria, has been published previously [15]. The study was approved by the institutional ethics review boards of centres of Cork University (Ireland), Glasgow University (Scotland) and Leiden University Medical Center (the Netherlands). Consent has been obtained from each patient or subject after full explanation of the purpose and nature of all procedures used.

\section{Kidney function}

At baseline creatinine levels were measured. Individuals with baseline creatinine levels over $200 \mu \mathrm{mol} / \mathrm{l}$ were excluded. GFR was estimated using the Modification of Diet in Renal Disease equation: eGFR $=186 \times \mathrm{Scr}^{(-1.154)}$ $x$ age ${ }^{(-0.203)} \times 0.742$ [if female], where Scr denotes serum creatinine level in $\mathrm{mg} / \mathrm{dl}$. It is assumed that all participants were of Northern European descent [16]. Statistical analysis of baseline characteristics was based on a comparison among subgroups of clinical stages of kidney failure based on eGFR, namely <30 (CKD stage 4), 3045 (CKD stage $3 \mathrm{~b}$ ), 45-60 (CKD stage $3 \mathrm{a}$ ) and $\geq 60 \mathrm{ml} /$ $\mathrm{min} / 1.73 \mathrm{~m}^{2}$ (CKD stage $1-2$ ) [17].

\section{Cognitive function and functional status}

Detailed description of the cognitive function and functional status measurements in PROSPER has been published previously $[18,19]$. Measurement of cognitive function and functional status were prespecified endpoints. One of the exclusion criteria was a poor cognitive function at baseline, measured by the Mini-Mental State Examination (MMSE). We used the generally used cut-off point of 24 ( of 30) points.

Outcome variables were derived from three other widely used neuropsychological performance tests in different cognitive domains and two functional status tests, as decline in functional status is largely driven by cognitive impairment. First, executive functioning was assessed using the Stroop Colour Word Test (Stroop) and the Letter-Digit Coding Test (LDT). Selective attention was assessed using Stroop, which consist of three parts, namely colour names, coloured patches and colour names printed in incongruously coloured ink. The time in seconds required to read the names or to identify colours is recorded [20]. We used an abbreviated version of the test with 40 elements [21]. Processing speed of general information was assessed using the LDT, which is a modification of the procedurally identical Symbol-Digits Modalities Test, which has an outcome variable of total number of correct entries completed in $60 \mathrm{~s}$ [22, 23]. Second, memory was assessed using the Picture-Word 
Learning Test. This verbal learning test is derived from the Groningen 15 Words Test. Outcomes are measured in three different trials and divided in recall (PLTi) and delayed recall (PLTd) after $20 \mathrm{~min}$ [24-26]. Functional status was assessed using two questionnaires, namely the Barthel Index and the Lawton Instrumental Activities of Daily Living Scale (IADL) [27, 28]. Barthel measures performance in basic activities of daily living and consists of 10 items. Barthel scores range from 0 to 20, with lower scores indicating more dependence. IADL evaluates more complex instrumental activities and includes 7 items. IADL scores range from 0 to 14, with again lower scores indicating more dependence. Cognitive function and functional status were tested at several time points, namely at baseline and after 9, 18 and 30 months, and at the end of the study.

\section{Statistical analysis}

All categorical data are presented as numbers with percentages and were compared using the chi-square test. All continuous data are presented as mean \pm standard deviation or median with interquartile range and were compared using an one-way ANOVA or Kruskal-Wallis test.

Means of cognitive function test scores and functional status scores at baseline were compared between the different CKD stages using a one-way ANOVA test. Furthermore, severe CKD stage 4 was compared to stage 12 (no CKD) using an independent t-test. For follow-up linear mixed models for repeated measurements were used, including the interim measures taken between the baseline and the final assessment. This last measurement varies between all participants between 36 and 48 months. Therefore all statistical analyses are performed with their individually varying time point, but we graphically display the results for the mean of these time points at 42 months. To preclude possible learning effects the pre-randomized measurement was discarded in all analyses. From the first PROSPER article about cognitive function, we know that all cognitive tests show a significant decline over time, confirming their adequate sensitivity to pick up deterioration of cognitive function in old age [19]. In the mixed model analyses CKD stages, time and CKD stage * time were included. Furthermore, to correct for confounders multiple prespecified fixed effects were included, namely sex, age, educational status, country, statin treatment, vascular confounders including history of vascular disease, hypertension, diabetes and current smoking, and other known confounders including objective measures as blood pressure, BMI, baseline lipids, haemoglobin, urea, NT-proBNP and troponin, all assessed as previously reported [15]. A logtransformation will be used for the variables with skewed distribution. Analyses will be repeated stratified for subjects with or without a history of vascular disease. The data were analysed using IBM SPSS Statistics version 23. $P$-values lower than 0.05 were considered statistically significant.

\section{Results}

Of the 5804 randomised patients, baseline creatinine levels were available for 5796 participants (99.9\%). Participants had a mean age of 75.3 years and $48.3 \%$ were male. Mean eGFR was $60.0 \pm 14.6 \mathrm{ml} / \mathrm{min} / 1.73 \mathrm{~m}^{2}$. In the prespecified stages of CKD, based on eGFR, 19 subjects $(0.33 \%)$ had a baseline eGFR of $<30 \mathrm{ml} / \mathrm{min} / 1.73 \mathrm{~m} 2$ (CKD stage 4), 786 (13.6\%) an eGFR between 30 and 45 $\mathrm{ml} / \mathrm{min} / 1.73 \mathrm{~m} 2$ (stage $3 \mathrm{~b}$ ), 2306 (39.8\%) an eGFR between 45 and $60 \mathrm{ml} / \mathrm{min} / 1.73 \mathrm{~m} 2$ (stage 3a), and 2685 (46.3\%) an eGFR $\geq 60 \mathrm{ml} / \mathrm{min} / 1.73 \mathrm{~m}^{2}$ (stage $1-2$ ).

Baseline characteristics are shown in Table 1, over strata of CKD stage and overall. Lower eGFR was significantly associated with older age, female sex, less years of education, more history of hypertension, vascular disease and medication use, and less history of diabetes and current smoking. Furthermore, lower eGFR was associated with an unfavorable lipid profile, higher levels of CRP, urea, NT-proBNP and troponin-T and lower levels of hemoglobin.

A higher score for Stroop or a lower score for the other five tests indicate a worse cognitive function or functional status. Non-adjusted baseline cognition and functional status scores are shown in Table 2, over strata of CKD stage and overall. The participants with the most impaired kidney function (CKD stage 4) had the worst cognitive function and functional status in all domains at baseline. When comparing the CKD stage 4 versus stage 1-2 mean scores $( \pm$ SE) were $74.2 \pm 6.7$ vs $69.3 \pm 0.6$ for Stroop $(p=0.514), 21.9 \pm$ 1.2 vs $21.9 \pm 0.2$ for $\operatorname{LDT}(p=0.951), 8.6 \pm 4.7$ versus $9.2 \pm 0.03$ for PLTi $(p=0.146), 9.8 \pm 0.8$ vs $10.1 \pm 0.04$ for PLTd $(p=0.600), 19.7 \pm 0.13$ vs $19.8 \pm 0.01$ for Barthel $(p=0.792)$ and $13.3 \pm 0.31$ vs $13.6 \pm 0.02$ for IADL $(p=0.172)$.

Mean follow-up was 42 months with a range of 36-48 months. Figure 1 shows the effect of CKD stage on the different cognitive function and functional status tests over time. The mean cognition and functional status scores are adjusted for all prespecified confounders. In all cognitive function tests, a trend was seen for faster cognitive decline over time in CKD stage 4 compared to the other CKD groups. No differences were seen for functional status. When comparing the most severe CKD stage $4\left(<30 \mathrm{ml} / \mathrm{min} / 1.73 \mathrm{~m}^{2}\right)$ versus stage $1-2$ (> $60 \mathrm{ml} / \mathrm{min} / 1.73 \mathrm{~m}^{2}$ ) over time the estimates $(95 \%$ confidence interval $(\mathrm{CI}))$ are $2.26(0.63-3.88 ; p=0.007)$ for Stroop, $-0.33(-0.66-0.00 ; p=0.050)$ for LDT, $0.08(-$ $0.06-0.21 ; p=0.274)$ for PLTi, $-0.07(-0.27-0.13 ; p=$ 
Table 1 Baseline Characteristics Split by Baseline CKD stages and Overall

\begin{tabular}{|c|c|c|c|c|c|c|}
\hline & \multirow{2}{*}{$\begin{array}{l}\text { Total } \\
n=5796\end{array}$} & \multicolumn{4}{|c|}{ CKD stages based on eGFR $\left(\mathrm{ml} / \mathrm{min} / 1.73 \mathrm{~m}^{2}\right)$} & \multirow[t]{2}{*}{$P$-value* } \\
\hline & & $\begin{array}{l}\text { Stage } 4 \\
n=19\end{array}$ & $\begin{array}{l}\text { Stage } 3 b \\
n=786\end{array}$ & $\begin{array}{l}\text { Stage 3a } \\
n=2306\end{array}$ & $\begin{array}{l}\text { Stage } 1 \text { and } 2 \\
n=2685\end{array}$ & \\
\hline Age (years) & $75.3 \pm 3.3$ & $77.4 \pm 3.1$ & $76.8 \pm 3.4$ & $75.3 \pm 3.3$ & $74.9 \pm 3.2$ & $<0.001$ \\
\hline Male gender & $2799(48.3)$ & 0 & $223(28.4)$ & $1029(44.6)$ & $1547(57.6)$ & $<0.001$ \\
\hline Education (years) & $15.1 \pm 2.0$ & $15.1 \pm 1.8$ & $14.8 \pm 1.6$ & $15.0 \pm 1.8$ & $15.4 \pm 2.3$ & $<0.001$ \\
\hline History of hypertension & $3585(61.9)$ & $18(94.7)$ & $568(72.3)$ & $1471(63.8)$ & $1528(56.9)$ & $<0.001$ \\
\hline History of diabetes & $622(10.7)$ & $1(5.3)$ & $68(8.7)$ & $221(9.6)$ & $332(12.4)$ & 0.002 \\
\hline History of vascular disease & $2561(44.2)$ & $7(36.8)$ & $400(50.9)$ & $1062(46.1)$ & $1092(40.7)$ & $<0.001$ \\
\hline History of stroke or TIA & $647(11.2)$ & $1(5.3)$ & $86(10.9)$ & $271(11.8)$ & $289(10.8)$ & 0.584 \\
\hline Current smoker & $1558(26.9)$ & $4(21.1)$ & $131(16.7)$ & $558(24.2)$ & $865(32.2)$ & $<0.001$ \\
\hline Number of medications & $3.6 \pm 2.3$ & $5.2 \pm 2.8$ & $4.5 \pm 2.3$ & $3.7 \pm 2.3$ & $3.2 \pm 2.2$ & $<0.001$ \\
\hline $\mathrm{SBP}(\mathrm{mmHg})$ & $154.7 \pm 21.8$ & $156.1 \pm 27.3$ & $154.8 \pm 22.2$ & $154.6 \pm 21.5$ & $154.6 \pm 22.0$ & 0.728 \\
\hline $\mathrm{DBP}(\mathrm{mmHg})$ & $83.8 \pm 11.4$ & $82.5 \pm 11.2$ & $83.1 \pm 10.7$ & $83.6 \pm 11.4$ & $84.1 \pm 11.6$ & $<0.001$ \\
\hline $\mathrm{BMI}\left(\mathrm{kg} / \mathrm{m}^{2}\right)$ & $26.8 \pm 4.2$ & $26.6 \pm 3.8$ & $27.6 \pm 4.4$ & $26.8 \pm 4.2$ & $26.6 \pm 4.1$ & $<0.001$ \\
\hline LDL-C (mmol/l) & $3.79 \pm 0.80$ & $4.06 \pm 0.93$ & $3.92 \pm 0.81$ & $3.85 \pm 0.81$ & $3.71 \pm 0.78$ & $<0.001$ \\
\hline $\mathrm{HDL}-\mathrm{C}(\mathrm{mmol} / \mathrm{l})$ & $1.28 \pm 0.35$ & $1.29 \pm 0.38$ & $1.25 \pm 0.34$ & $1.28 \pm 0.35$ & $1.29 \pm 0.35$ & $<0.001$ \\
\hline Total cholesterol (mmol/l) & $5.68 \pm 0.91$ & $6.02 \pm 1.03$ & $5.88 \pm 0.94$ & $5.74 \pm 0.87$ & $5.57 \pm 0.87$ & $<0.001$ \\
\hline Triglyceride (mmol/l) & $1.54 \pm 0.70$ & $1.85 \pm 0.74$ & $1.76 \pm 0.77$ & $1.57 \pm 0.69$ & $1.46 \pm 0.68$ & $<0.001$ \\
\hline Glucose $(\mathrm{mmol} / \mathrm{l})$ & $5.5 \pm 1.4$ & $5.13 \pm 0.94$ & $5.56 \pm 1.40$ & $5.50 \pm 1.31$ & $5.4 \pm 1.6$ & $<0.001$ \\
\hline CRP at 6 months $(\mathrm{mg} / \mathrm{l})$ & $2.3[1.1-4.5]$ & $4.2[2.1-10.1]$ & $2.8[1.4-5.7]$ & $2.3[1.1-4.6]$ & $2.1[1.0-4.1]$ & $<0.001$ \\
\hline Urea (mg/dL) & $6.3 \pm 1.8$ & $10.5 \pm 1.8$ & $7.9 \pm 2.3$ & $6.4 \pm 1.6$ & $5.8 \pm 1.5$ & $<0.001$ \\
\hline $\mathrm{Hb}(\mathrm{mmol} / \mathrm{L})$ & $8.7 \pm 0.8$ & $8.4 \pm 0.7$ & $8.4 \pm 0.8$ & $8.7 \pm 0.8$ & $8.8 \pm 0.8$ & $<0.001$ \\
\hline NT-proBNP at 6 months (ng/l) & 148.7 [79.5-289.3] & $417.0[283.9-789.0]$ & $230.2[122.1-489.1]$ & 151.5 [81.4-293.9] & $127.6[70.0-238.8]$ & $<0.001$ \\
\hline Troponin at 6 months $(\mu \mathrm{g} / \mathrm{l})$ & $0.010 \pm 0.036$ & $0.016 \pm 0.010$ & $0.013 \pm 0.017$ & $0.010 \pm 0.042$ & $0.010 \pm 0.036$ & $<0.001$ \\
\hline
\end{tabular}

All values are presented as $n(\%)$, mean $\pm \mathrm{SD}$ or median [IQR]. ${ }^{*} p$-values of categorical data were assessed using the chi-square test and $p$-values of the continuous data were assessed using an one-way ANOVA test or a Kruskal-Wallis test. Abbreviations: BMI Body mass index, CKD Chronic kidney disease, CRP Creactive protein, DBP Diastolic blood pressure, eGFR Estimated glomerular filtration rate, Hb Haemoglobin, HDL High-density lipoprotein, $L D L$ Low-density lipoprotein, NT-proBNP N-terminal pro b-type natriuretic peptide, SBP Systolic blood pressure, SD Standard deviation, TIA Transient ischemic attack

$0.503)$ for PLTd, $-0.01 \quad(-0.11-0.08 ; p=0.766)$ for Barthel and $0.03(-0.09-0.15 ; 0.622)$ for IADL, see also Fig. 1. Participants with mild to modest CKD stage 3 compared to CKD stage 1-2 had no worse cognitive function, which is also seen in Fig. 1, displaying practically parallel lines for CKD stages 3 to 1 .

\section{Stratification for history of vascular disease}

In Fig. 2 the analysis was stratified according to the history of vascular disease. The trend of faster cognitive decline over time in CKD stage 4 compared to the other CKD groups was most prevalent in patients with a history of vascular disease compared to patients without a

Table 2 Cognitive Function at Baseline Over Strata of CKD stages and Overall

\begin{tabular}{|c|c|c|c|c|c|c|}
\hline & \multirow{2}{*}{$\begin{array}{l}\text { Total } \\
n=5796\end{array}$} & \multicolumn{4}{|c|}{ CKD stages based on eGFR $\left(\mathrm{ml} / \mathrm{min} / 1.73 \mathrm{~m}^{2}\right)$} & \multirow[t]{2}{*}{$P$-value* } \\
\hline & & $\begin{array}{l}\text { Stage } 4 \\
n=19\end{array}$ & $\begin{array}{l}\text { Stage } 3 b \\
n=786\end{array}$ & $\begin{array}{l}\text { Stage 3a } \\
n=2306\end{array}$ & $\begin{array}{l}\text { Stage } 1 \text { and } 2 \\
n=2685\end{array}$ & \\
\hline Stroop-Colour-Word Test & $66.5 \pm 0.4$ & $74.2 \pm 6.7$ & $66.4 \pm 0.9$ & $63.2 \pm 0.5$ & $69.3 \pm 0.6$ & $<0.001$ \\
\hline Letter-Digit Coding Test & $23.1 \pm 0.1$ & $21.9 \pm 1.2$ & $23.3 \pm 0.3$ & $24.4 \pm 0.2$ & $21.9 \pm 0.2$ & $<0.001$ \\
\hline Picture-Word Learning Test - immediate & $9.3 \pm 0.03$ & $8.6 \pm 4.7$ & $9.3 \pm 0.07$ & $9.4 \pm 0.04$ & $9.2 \pm 0.03$ & 0.001 \\
\hline Picture-Word Learning Test - delayed & $10.1 \pm 0.04$ & $9.8 \pm 0.8$ & $10.0 \pm 0.1$ & $10.2 \pm 0.05$ & $10.1 \pm 0.04$ & 0.197 \\
\hline The Barthel index & $19.8 \pm 0.01$ & $19.7 \pm 0.13$ & $19.7 \pm 0.03$ & $19.8 \pm 0.01$ & $19.8 \pm 0.01$ & 0.004 \\
\hline Instrumental Activities of Daily Living & $13.6 \pm 0.01$ & $13.3 \pm 0.31$ & $13.5 \pm 0.04$ & $13.7 \pm 0.02$ & $13.6 \pm 0.02$ & 0.008 \\
\hline
\end{tabular}

All values are presented as mean \pm SE. * $p$-values of differences between groups were assessed using an one-way ANOVA test. Abbreviations: CKD Chronic kidney disease, eGFR estimated glomerular filtration rate, SE Standard error 

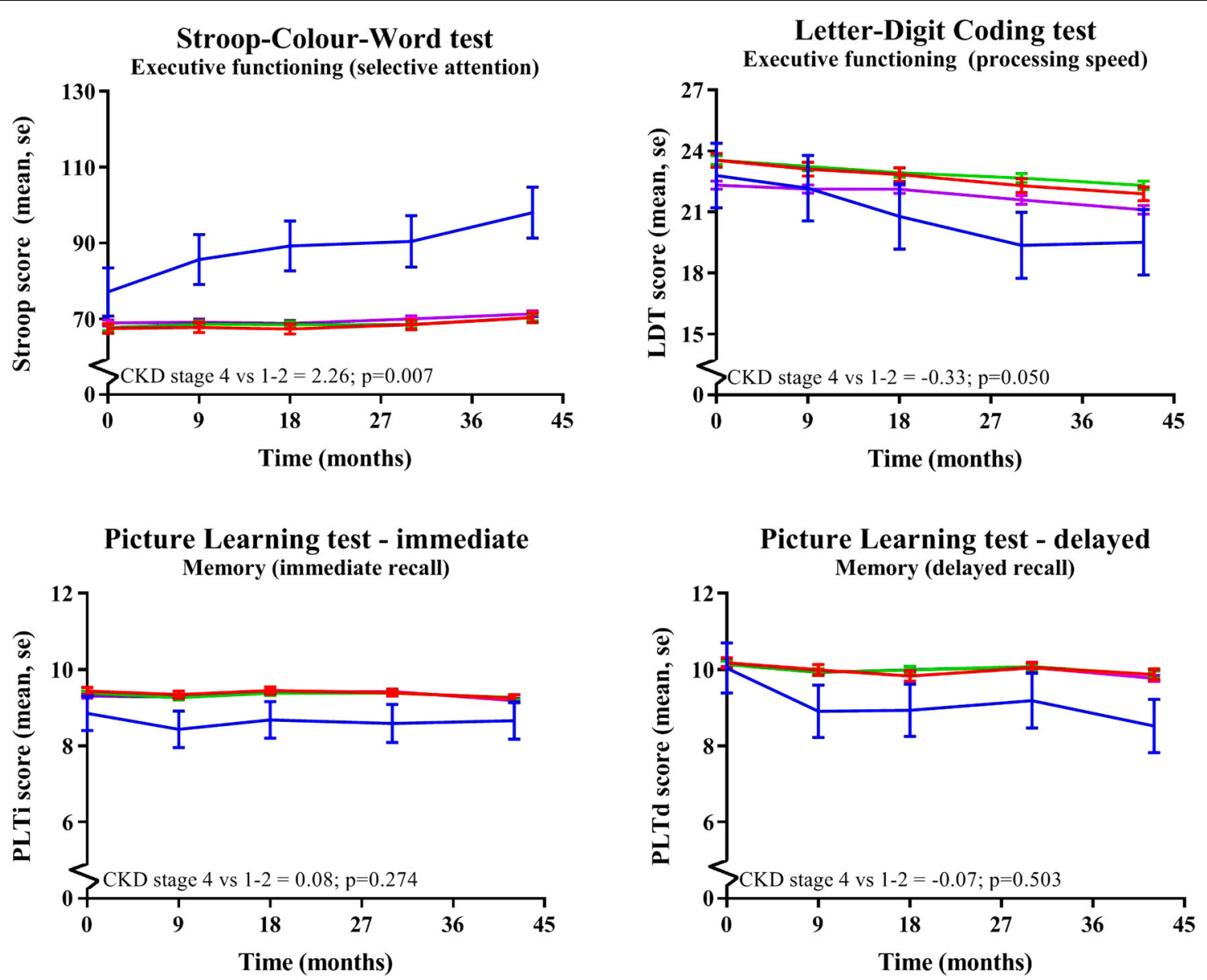

Barthel index

Basic activities of daily living

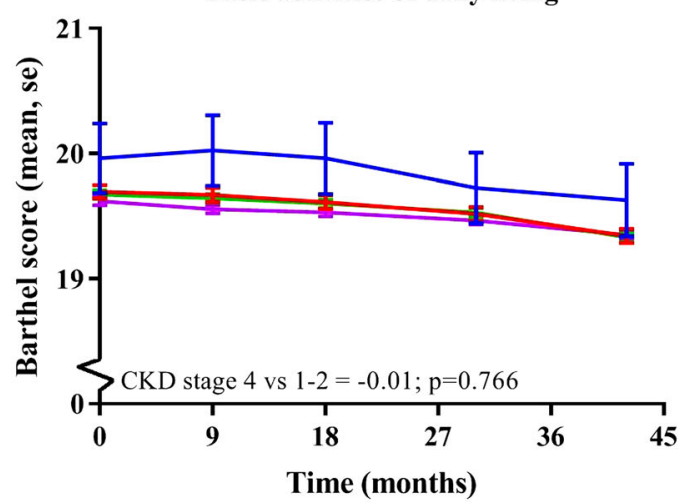

The Lawton IADL scale

Complex instrumental activities
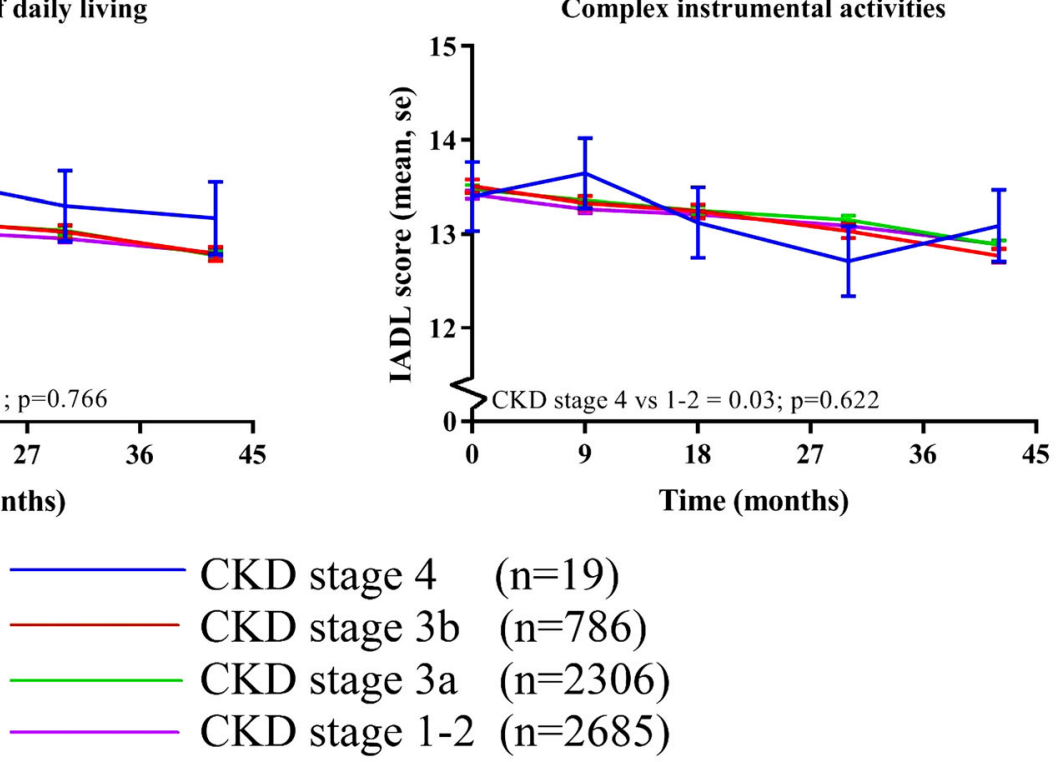

Fig. 1 (See legend on next page.) 
(See figure on previous page.)

Fig. 1 Effect of CKD stage on cognitive function and functional status over time. * Means were assessed using linear mixed models adjusted for prespecified variables including sex, age, educational status, country, statin treatment and multiple other known vascular confounders. $P$-values represent the statistical significance of the difference in cognitive test score changes over time between CKD stage $4\left(\mathrm{eGFR}<30 \mathrm{ml} / \mathrm{min}_{1} 1.73 \mathrm{~m}^{2}\right)$ versus CKD stage 1-2 (eGFR> $60 \mathrm{ml} / \mathrm{min} / 1.73 \mathrm{~m}^{2}$ ). Abbreviations: Barthel, the Barthel index; eGFR, estimated glomerular filtration rate; IADL, Instrumental Activities of Daily Living; LDT, Letter-Digit Coding Test; PLTd, Picture-Word Learning Test - delayed; PLTi, Picture-Word Learning Test - immediate; Stroop, Stroop-Colour-Word Test

history of vascular disease, see Fig. 2 and Table 3. No differences were found for functional status. Estimates (95\% CI) of CKD stage 4 versus stage $1-2$ in patients with a history of vascular disease are 6.52 (3.94-9.10; $p<0.0001)$ for Stroop, $-1.00(-1.62--0.37 ; p=0.002)$ for LDT, $0.16(-0.08-0.40 ; p=0.180)$ for PLTi, -0.02 $(-0.37-0.34 ; p=0.930)$ for PLTd, $0.01(-0.16-0.18 ; p=$ $0.940)$ for Barthel and $0.06(-0.15-0.28 ; p=0.562)$ for IADL. Estimates $(95 \% \mathrm{CI})$ of CKD stage 4 versus stage $1-2$ in patients without a history of vascular disease are $-0.11(-2.21-1.99 ; p=0.919)$ for Stroop, $-0.08(-0.47-$ $0.32 ; p=0.694)$ for LDT, $0.03(-0.13-0.20 ; p=0.695)$ for PLTi, $-0.09(-0.33-0.15 ; p=0.485)$ for PLTd, -0.02 ($0.13-0.18 ; p=0.642)$ for Barthel and $0.01(-0.12-0.15$; $p=0.868$ ) for IADL, see also Table 3. Corresponding $p$ values for interaction of vascular disease and cognitive decline or functional decline over time were 0.016 for Stroop, 0.115 for LDT, 0.529 for PLTi, 0.123 for PLTd, 0.737 for Barthel and 0.064 for IADL.

\section{Discussion}

In this large cohort of older people with an increased risk for, or a history of, vascular disease, only severe kidney disease (CKD stage 4), but not mild to modest kidney disease (CKD stage $3 a$ and $b$ ), was associated with cognitive impairment at baseline and cognitive decline over time. The association of severe kidney disease with cognitive impairment and decline over time was more outspoken in patients with a history of vascular disease. No association was found between kidney function and functional status.

Severe kidney failure as independent risk factor for cognitive dysfunction, in combination with lack of effect of the association of mild to modest kidney failure, has been found in previous research $[29,30]$. This might be due to the fact that nephrogenic risk factors only start playing a role in more advanced CKD [13]. Patients that do have cognitive dysfunction in earlier stages of CKD might have worse cognitive function mainly related to vascular damage. Because it is known from previous studies that a history of vascular disease or risk factors as hypertension can lead to microvascular damage and small vessel disease in the brain, CKD can ultimately lead to cognitive dysfunction via this pathway $[8,9]$. Furthermore, impaired cardiac function, measured by NT-
proBNP or Troponin, is associated with cognitive dysfunction independently from other cardiovascular risk factors [31-33]. As expected, also in this study, a potential predictor for worse cognitive function at baseline in multivariate analysis was a higher vascular burden, as shown before in this cohort $[19,34]$.

The contribution of kidney failure to cognitive dysfunction on top of a high vascular burden versus no vascular burden remained hitherto mostly unknown. In general, it is difficult to make a distinction between cognitive decline in CKD patients with or without vascular risk factors, because many CKD patients have a vascular aetiology of their kidney failure, for instance due to hypertension or diabetes mellitus. In this cohort $44.2 \%$ of participants were included with a history of vascular disease, $61.9 \%$ had hypertension and $10.7 \%$ had diabetes. Therefore, we used stratification to distinguish patients with proven vascular disease from patients with only vascular risk factors. Cognitive function declined faster over time in patients with CKD stage $4(<30 \mathrm{ml} / \mathrm{min} /$ $1.73 \mathrm{~m}^{2}$ ) especially together with a history of vascular disease. In a comparable subanalysis, Seidel et al. also showed increasing prevalence of depression and cognitive dysfunction in the CVD group (defined as coronary heart disease or myocardial infarction) compared to no CVD in the higher CKD-stages compared to controls [35].

As previous research has been shown, decline in kidney function associates with a higher risk of stroke, partly due to a higher incidence in atrial fibrillation [36, 37]. Approximately $10 \%$ of patients develop new-onset dementia after first stroke, and even more after recurrent stroke [38, 39]. According to the U.S. Renal Data System prevalence of atrial fibrillation in patients with or without CKD is $24.0 \%$ versus $9.5 \%$ and prevalence of CVA or TIA is $19.4 \%$ versus $7.7 \%$. Prevalence of both diseases increases with increasing stage of kidney failure [40]. Therefore, a history of stroke or TIA, which is one of the inclusion criteria in this study, could be a confounder considering the influence on cognitive impairment. In the total group $11.2 \%$ had a history of stroke or TIA, which did not differ significantly between groups $(p=0.584) ; 1$ (5.3\%), 86 (10.9\%), 271 (11.8\%) and $289(10.8 \%)$ in the CKD stage 4, stage 3b, stage 3a and stage 1-2 respectively. Therefore, the worse cognitive function in CKD stage 4 , appears unlikely to be explained by the prevalence of stroke or TIA. 

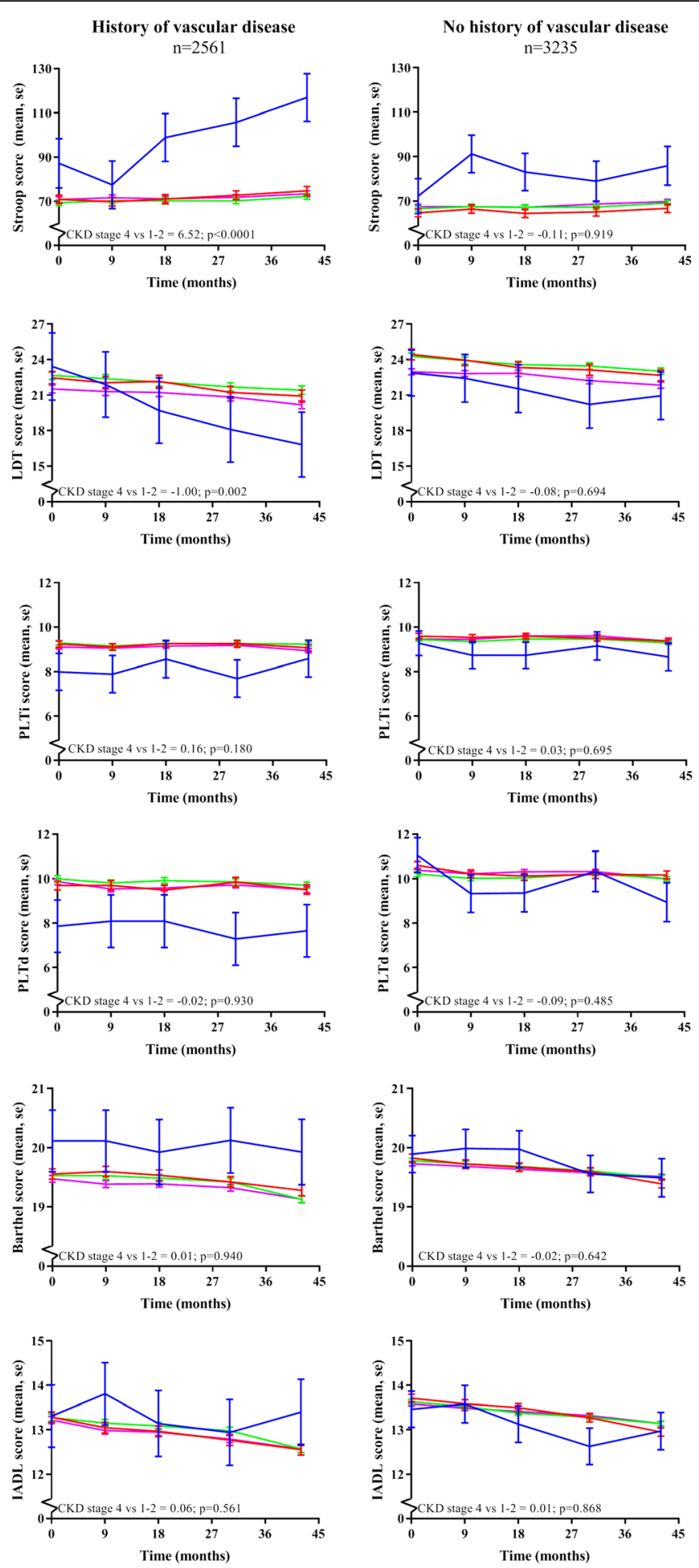

CKD stage $4 \quad(n=19)$

CKD stage $3 b \quad(n=786)$

CKD stage $3 a \quad(n=2306)$

CKD stage $1-2 \quad(n=2685)$

Fig. 2 (See legend on next page.) 
(See figure on previous page.)

Fig. 2 Effect of CKD stage on cognitive function and functional status over time stratified for history of vascular disease. ${ }^{*}$ Means were assessed using linear mixed models adjusted for prespecified variables including sex, age, educational status, country, statin treatment and multiple other known vascular confounders. P-values represent the statistical significance of the difference in cognitive test score changes over time between CKD stage 4 (eGFR $\left.<30 \mathrm{ml} / \mathrm{min} / 1.73 \mathrm{~m}^{2}\right)$ versus CKD stage 1-2 (eGFR> $\left.60 \mathrm{ml} / \mathrm{min} / 1.73 \mathrm{~m}^{2}\right)$. Abbreviations: Barthel, the Barthel index; eGFR, estimated glomerular filtration rate; IADL, Instrumental Activities of Daily Living; LDT, Letter-Digit Coding Test; PLTd, Picture-Word Learning Test delayed; PLTi, Picture-Word Learning Test - immediate; Stroop, Stroop-Colour-Word Test

Established previously in PROSPER, impaired kidney function was independently associated with increased risk of all-cause mortality, fatal vascular events and with composite fatal and nonfatal coronary and heart failure outcomes. This effect was most prevalent in eGFR $<40$ $\mathrm{ml} / \mathrm{min} / 1.73 \mathrm{~m}^{2}$. Notably, the PROSPER investigators did not find an association between an impaired eGFR and a higher risk of stroke [41]. However, not only impaired kidney function increases the risk of mortality, but it is also known, that next to the importance to prevent cognitive decline for better quality of life of patients, a worse cognitive function associates with higher morbidity and mortality rates in older patients reaching endstage kidney disease [42-44].

The difference in cognitive decline for CKD stage 4 and CKD stage 1-2 might be partially explained by the sex difference between the groups. However, a sexdifference in cognitive decline is debated. A review showed that sex did not determine the rate of cognitive decline between ages of $60-80$ years, an age that is comparable to our cohort that included patients between 70 and 82 years [45].. In our cohort univariate male sex correlated with worse cognitive function, however multivariate analysis showed still worse memory tests compared to females, but better cognitive function in executive function (data not shown). These results are comparable with a study by Proust-Lima et al., whereby older women showed better outcomes in memory tests, whereas men had a better visuospatial ability [46]. Therefore, the lack of males in the CKD stage 4 cannot explain the worse outcome in that category.

\section{Limitations}

Our study has several limitations. First of all, our population was selected for a specific clinical trial and do not represent the general population.

Another limitation is that we were restricted to eGFR in our measures of kidney function, other predictors as albuminuria or cystatin $\mathrm{C}$ are not available. A recent systematic review and meta-analysis of prospective, population-based studies, showed that albuminuria was most consistent as marker of CKD in the association with cognitive decline with an odds ratio of 1.35 (95\% CI 1.06-1.73). An eGFR $<60 \mathrm{ml} / \mathrm{min} / 1.73 \mathrm{~m}^{2}$ showed no significant association with cognitive dysfunction, consistent with our results, with an odds ratio of 1.28 (95\% CI 0.99-1.65) [47]. In our cohort the same analyses with creatinine instead of eGFR yielded similar results that were inversely proportional as expected (data not shown). Furthermore, no distinction can be made between acute or chronic kidney failure. Creatinine was only measured at baseline, so no follow-up measurements are available, therefore it is not known whether patients with a normal kidney function at baseline deteriorated or patients with an impaired kidney function improved over time. In addition, it would be interesting to see whether patients with a faster cognitive decline also have a faster decline in kidney function, considering that both the brain and kidney share similar hemodynamic characteristics, since both are low resistance end organs exposed to high-volume blood flow and therefore predisposed for vascular damage $[4,48]$.

Table 3 Effect of CKD stage 4 versus stage 1-2 on cognitive function over time

\begin{tabular}{|c|c|c|c|c|c|c|c|}
\hline & \multicolumn{2}{|l|}{ Total } & \multicolumn{2}{|c|}{ History of vascular disease } & \multicolumn{2}{|c|}{$\begin{array}{l}\text { No history of vascular } \\
\text { disease }\end{array}$} & \multirow{2}{*}{$\begin{array}{l}\text { interactior } \\
p \text {-value }\end{array}$} \\
\hline & Beta $(95 \% \mathrm{Cl})$ & $p$-value & Beta $(95 \% \mathrm{Cl})$ & $p$-value & Beta $(95 \% \mathrm{Cl})$ & $p$-value & \\
\hline Stroop-Colour-Word Test & $2.26(0.63-3.88)$ & 0.007 & $6.52(3.94-9.10)$ & $<0.0001$ & $-0.11(-2.21-1.99)$ & 0.919 & 0.016 \\
\hline Letter-Digit Coding Test & $-0.33(-0.66-0.00)$ & 0.050 & $-1.00(-1.62--0.37)$ & 0.002 & $-0.08(-0.47-0.32)$ & 0.694 & 0.115 \\
\hline Picture-Word Learning Test - immediate & $0.08(-0.06-0.21)$ & 0.274 & $0.16(-0.08-0.40)$ & 0.180 & $0.03(-0.13-0.20)$ & 0.695 & 0.529 \\
\hline Picture-Word Learning Test - delayed & $-0.07(-0.27-0.13)$ & 0.503 & $-0.02(-0.37-0.34)$ & 0.930 & $-0.09(-0.33-0.15)$ & 0.485 & 0.123 \\
\hline The Barthel index & $-0.01(-0.11-0.08)$ & 0.766 & $0.01(-0.16-0.18)$ & 0.940 & $-0.02(-0.13-0.08)$ & 0.642 & 0.737 \\
\hline Instrumental Activities of Daily Living & $0.03(-0.09-0.15)$ & 0.622 & $0.06(-0.15-0.28)$ & 0.561 & $0.01(-0.12-0.15)$ & 0.868 & 0.064 \\
\hline
\end{tabular}

* $p$-values of differences in cognitive test score changes over time were assessed between CKD stage 4 (eGFR $<30 \mathrm{ml} / \mathrm{min} / 1.73 \mathrm{~m}^{2}$ ) versus CKD stage $1-2$ (eGFR $>$ $60 \mathrm{ml} / \mathrm{min} / 1.73 \mathrm{~m}^{2}$ ) using linear mixed models adjusted for prespecified variables including sex, age, educational status, country, statin treatment and multiple other known vascular confounders 
Whereas one of the exclusion criteria was a high creatinine at baseline and the groups of eGFR were divided based on clinical stages, the group containing CKD stage 4 was relatively small (after stratification only seven participants with and 12 participants without a history of vascular disease). Therefore, although the results of CKD stage 4 appear clinically relevant, especially in the cognitive function analysis over time (Figs. 1 and 2), significance remained partly absent and therefore results needs to be interpreted with caution. Furthermore, although the results of the cognitive function tests show the same trend in both cognitive domains, the effect on executive functioning seems statistically larger than the effect on memory. Possible explanation could be that executive functioning seems most often sooner affected than memory, partly due to more sensitive executive function tests, and memory would be more affected over a longer follow-up period.

\section{Conclusions}

In this study, only severe kidney disease (CKD stage 4) seem to be associated with cognitive impairment at baseline and cognitive decline over time. A mild to modest impaired kidney function appeared not to be independently associated with cognitive decline during a 3.2 year follow-up period. For better understanding of the mechanisms involved in cognitive decline in CKD, especially end-stage kidney disease, additional studies are necessary, which may contribute to interventions for prevention. Combined (metabolic) parameters of kidney function, beside eGFR, should be taken into account, as well as albuminuria. An observational study is currently under way to gain insight in the potential different mechanisms of cognitive decline in older patients with end-stage kidney disease to identify modifiable risk factors [49]. Furthermore, it would be of great interest to determine whether newer agents which seem to meaningfully slow renal function decline such as SGLT2 inhibitors, also slow decline in cognitive function, although we accept such agents may also lessens risks in cardiovascular disease [50].

\begin{abstract}
Abbreviations
Barthel: The Barthel index; BMI: Body mass index; Cl: Confidence interval; CKD: Chronic kidney disease; CRP: C-reactive protein; CVA: Cerebrovascular accident; DBP: Diastolic blood pressure; eGFR: estimated glomerular filtration rate; Hb: Hemoglobin; HDL: High-density lipoprotein; IADL: Instrumental Activities of Daily Living; LDL: Low-density lipoprotein; LDT: Letter-Digit Coding Test; MMSE: Mini-Mental State Examination; NT-proBNP: N-terminal pro b-type natriuretic peptide; OR: Odds ratio; PLTd: Picture-Word Learning Test - delayed recall; PLTi: Picture-Word Learning Test - immediate recall; PROSPER: The PROspective Study of Pravastatin in the Elderly at Risk; SBP: Systolic blood pressure; Stroop: Stroop-Colour-Word Test; TIA: Transient ischemic attack
\end{abstract}

\section{Acknowledgements}

The abstract of this study has been published before as a meeting abstract: 'Zijistra L, Trompet S, Mooijaart SP, van Buren M \& Jukema J. Impaired Renal
Function And Cognitive Decline In Elderly With Vascular Burden. Journal of the American College of Cardiology 2019; 73 [9]: 2068'.

\section{Authors' contributions}

LEZ Conception and design of the study; analysis and interpretation of data; drafting of the manuscript; providing intellectual content of critical importance to the work described; final approval of the manuscript. ST Conception and design of the study; analysis and interpretation of data; drafting of the manuscript; providing intellectual content of critical importance to the work described; final approval of the manuscript. SPM Conception and design of the study; analysis and interpretation of data; drafting of the manuscript; providing intellectual content of critical importance to the work described; final approval of the manuscript. MvB Analysis and interpretation of data; revising of the manuscript; providing intellectual content of critical importance to the work described; final approval of the manuscript. NS Analysis and interpretation of data; revising of the manuscript; providing intellectual content of critical importance to the work described; final approval of the manuscript. DJS Analysis and interpretation of data; revising of the manuscript; providing intellectual content of critical importance to the work described; final approval of the manuscript. JWJ Conception and design of the study; analysis and interpretation of data; revising of the manuscript; providing intellectual content of critical importance to the work described; final approval of the manuscript

\section{Funding}

The Prospective Study of Pravastatin in the Elderly at Risk (PROSPER) trial was supported by an unrestricted investigator-initiated grant from Bristol-Myers Squibb, USA. The funding body had no role in the design of the current study and collection; analysis; and interpretation of data; and in writing the manuscript.

\section{Availability of data and materials}

The datasets used and/or analysed during the current study are available from the corresponding author on reasonable request.

\section{Ethics approval and consent to participate}

The study was approved by the institutional ethics review boards of centres of Cork University (Ireland), Glasgow University (Scotland) and Leiden University Medical Center (the Netherlands) and all participants gave written informed consent.

\section{Consent for publication}

Not applicable.

\section{Competing interests}

Dr. Stott received a grant from Bristol-Myers Squibb. No other competing conflicts of interest, financial or otherwise, are declared by the authors.

\section{Author details}

'Department of Cardiology, Leiden University Medical Center, Albinusdreef 2, 2333ZA, Leiden, The Netherlands. ${ }^{2}$ Department of Gerontology and Geriatrics, Leiden University Medical Center, Albinusdreef 2, 2333ZA, Leiden, The Netherlands. ${ }^{3}$ Department of Nephrology, Leiden University Medical Center, Albinusdreef 2, 2333ZA, Leiden, The Netherlands. ${ }^{4}$ Department of Internal Medicine, HagaHospital, Els Borst-Eilersplein 275, 2545AA, The Hague, The Netherlands. ${ }^{5} \mathrm{BHF}$ Glasgow Cardiovascular Research Centre, Faculty of Medicine, Glasgow G12 8TD, UK. ${ }^{6}$ Institute of Cardiovascular and Medical Sciences, College of Medical, Veterinary and Life Sciences, University of Glasgow, 126 University Place, G12 8TA, Glasgow, UK.

Received: 29 May 2019 Accepted: 27 February 2020

Published online: 05 March 2020

\section{References}

1. Pippias M, Stel VS, Abad Diez JM, Afentakis N, Herrero-Calvo JA, Arias M, et al. Renal replacement therapy in Europe: a summary of the 2012 ERAEDTA registry annual report. Clin Kidney J. 2015;8(3):248-61.

2. Saran R, Robinson B, Abbott KC, Agodoa LYC, Bhave N, Bragg-Gresham J, et al. US renal data system 2017 annual data report: epidemiology of kidney disease in the United States. Am J Kidney Dis. 2018;71(3s1):A7. 
3. Petersen RC, Lopez O, Armstrong MJ, Getchius TSD, Ganguli M, Gloss D, et al. Practice guideline update summary: mild cognitive impairment: report of the guideline development, dissemination, and implementation Subcommittee of the American Academy of neurology. Neurology. 2018;90(3):126-35.

4. Bugnicourt JM, Godefroy O, Chillon JM, Choukroun G, Massy ZA. Cognitive disorders and dementia in CKD: the neglected kidney-brain axis. J Am Soc Nephrol. 2013;24(3):353-63.

5. Reitz C, Tang MX, Manly J, Mayeux R, Luchsinger JA. Hypertension and the risk of mild cognitive impairment. Arch Neurol. 2007;64(12):1734-40.

6. Livingston G, Sommerlad A, Orgeta V, Costafreda SG, Huntley J, Ames D, et al. Dementia prevention, intervention, and care. Lancet (London, England). 2017;390(10113):2673-734.

7. Ikram MA, Vernooij MW, Hofman A, Niessen WJ, van der Lugt A, Breteler MM. Kidney function is related to cerebral small vessel disease. Stroke. 2008; 39(1):55-61.

8. Pantoni L. Cerebral small vessel disease: from pathogenesis and clinical characteristics to therapeutic challenges. Lancet Neurol. 2010;9(7):689-701.

9. Thompson CS, Hakim AM. Living beyond our physiological means: small vessel disease of the brain is an expression of a systemic failure in arteriolar function: a unifying hypothesis. Stroke. 2009;40(5):e322-30.

10. Kurella Tamura M, Xie D, Yaffe K, Cohen DL, Teal V, Kasner SE, et al. Vascular risk factors and cognitive impairment in chronic kidney disease: the chronic renal insufficiency cohort (CRIC) study. Clin J Am Soc Nephrol. 2011;6(2):248-56.

11. Etgen T, Chonchol M, Forstl H, Sander D. Chronic kidney disease and cognitive impairment: a systematic review and meta-analysis. Am J Nephrol. 2012;35(5):474-82.

12. Elias MF, Dore GA, Davey A. Kidney disease and cognitive function. Contrib Nephrol. 2013;179:42-57.

13. Watanabe K, Watanabe T, Nakayama M. Cerebro-renal interactions: impact of uremic toxins on cognitive function. Neurotoxicology. 2014;44:184-93.

14. Sarnak MJ, Tighiouart H, Scott TM, Lou KV, Sorensen EP, Giang LM, et al. Frequency of and risk factors for poor cognitive performance in hemodialysis patients. Neurology. 2013;80(5):471-80.

15. Shepherd J, Blauw GJ, Murphy MB, Cobbe SM, Bollen EL, Buckley BM, et al. The design of a prospective study of pravastatin in the elderly at risk (PROSPER). PROSPER study group. PROspective study of pravastatin in the elderly at risk. Am J Cardiol. 1999;84(10):1192-7.

16. Levey AS, Bosch JP, Lewis JB, Greene T, Rogers N, Roth D. A more accurate method to estimate glomerular filtration rate from serum creatinine: a new prediction equation. Modification of diet in renal disease study group. Ann Intern Med. 1999;130(6):461-70.

17. Levey AS, Coresh J, Bolton K, Culleton B, Harvey KS, Ikizler TA, et al. KDDOO clinical practice guidelines for chronic kidney disease: evaluation, classification, and stratification. Am J Kidney Dis. 2002;39(2 Suppl 1):S1-266

18. Houx PJ, Shepherd J, Blauw GJ, Murphy MB, Ford I, Bollen EL, et al. Testing cognitive function in elderly populations: the PROSPER study. PROspective study of pravastatin in the elderly at risk. J Neurol Neurosurg Psychiatry. 2002;73(4):385-9.

19. Trompet $S$, van Vliet $P$, de Craen AJ, Jolles J, Buckley BM, Murphy MB, et al Pravastatin and cognitive function in the elderly. Results of the PROSPER study. J Neurol. 2010;257(1):85-90.

20. Houx PJ, Jolles J, Vreeling FW. Stroop interference: aging effects assessed with the Stroop color-word test. Exp Aging Res. 1993;19(3):209-24.

21. Klein M, Ponds RW, Houx PJ, Jolles J. Effect of test duration on age-related differences in Stroop interference. J Clin Exp Neuropsychol. 1997;19(1):77-82.

22. Smith A. The symbol digit modalities test. A neuropsychologic test for economic screening of learning and other cerebral disorders. Learn Disord. 1968;3:82-91.

23. Lezak M. Verbal functions and language skills. 2nd ed; 1995.

24. Rey A. L'examen psychologique dans les cas d'encephalopathie traumatique. Paris: Presses Universitaires de France; 1964.

25. Brand N, Jolles J. Learning and retrieval rate of words presented auditorily and visually. J Gen Psychol. 1985;112(2):201-10.

26. Deelman BG, Brouwer WH, Zomeren AHv, Saan RJ. Functiestoornissen na trauma capitis. In: Jennekens-Schinkel A, Diamant JJ, Diesfeldt HFA, Haaxma R, editors. Neuropsychologie in Nederland. Deventer: Van Loghum Slaterus; 1980. p 253-81.

27. Mahoney FI, Barthel DW. Functional evaluation: the BARTHEL index Maryland State Med J. 1965;14:61-5.

28. Lawton MP. The functional assessment of elderly people. J Am Geriatr Soc 1971;19(6):465-81.
29. Kurella M, Yaffe K, Shlipak MG, Wenger NK, Chertow GM. Chronic kidney disease and cognitive impairment in menopausal women. Am J Kidney Dis. 2005;45(1):66-76.

30. Chaiben VBO, Silveira TBD, Guedes MH, Fernandes JPA, Ferreira JHF, Beltrao $J$, et al. Cognition and renal function: findings from a Brazilian population. J Bras Nefrol. 2018;41(2):200.

31. Bertens AS, Sabayan B, de Craen AJM, Van der Mast RC, Gussekloo J. High sensitivity cardiac troponin $T$ and cognitive function in the oldest old: the Leiden 85-plus study. J Alzheimers Dis. 2017;60(1):235-42.

32. Hilal S, Chai YL, Ikram MK, Elangovan S, Yeow TB, Xin X, et al. Markers of cardiac dysfunction in cognitive impairment and dementia. Medicine. 2015;94(1):e297.

33. Schneider AL, Rawlings AM, Sharrett AR, Alonso A, Mosley TH, Hoogeveen $\mathrm{RC}$, et al. High-sensitivity cardiac troponin $\mathrm{T}$ and cognitive function and dementia risk: the atherosclerosis risk in communities study. Eur Heart J. 2014:35(27):1817-24.

34. Wijsman LW, de Craen AJ, Trompet S, Sabayan B, Muller M, Stott DJ, et al. High-sensitivity cardiac troponin $T$ is associated with cognitive decline in older adults at high cardiovascular risk. Eur J Prev Cardiol. 2016;23(13):1383-92.

35. Seidel UK, Gronewold J, Volsek M, Todica O, Kribben A, Bruck H, et al. Physical, cognitive and emotional factors contributing to quality of life, functional health and participation in community dwelling in chronic kidney disease. PLoS One. 2014;9(3):e91176.

36. Nakayama M, Metoki H, Terawaki H, Ohkubo T, Kikuya M, Sato T, et al. Kidney dysfunction as a risk factor for first symptomatic stroke events in a general Japanese population--the Ohasama study. Nephrol Dial Transplant. 2007;22(7):1910-5.

37. Chillon JM, Massy ZA, Stengel B. Neurological complications in chronic kidney disease patients. Nephrol Dial Transplant. 2016;31(10):1606-14.

38. Gottesman RF, Hillis AE. Predictors and assessment of cognitive dysfunction resulting from ischaemic stroke. Lancet Neurol. 2010;9(9):895-905.

39. Pendlebury ST, Rothwell PM. Prevalence, incidence, and factors associated with pre-stroke and post-stroke dementia: a systematic review and metaanalysis. Lancet Neurol. 2009:8(11):1006-18.

40. U.S. Renal Data System. USRDS 2013 annual data report: atlas of chronic kidney disease and end-stage renal disease in the United States. Bethesda: National Institutes of Health, National Institute of Diabetes and Digestive and Kidney Diseases; 2013.

41. Ford I, Bezlyak V, Stott DJ, Sattar N, Packard CJ, Perry I, et al. Reduced glomerular filtration rate and its association with clinical outcome in older patients at risk of vascular events: secondary analysis. PLoS Med. 2009;6(1):e16.

42. Kallenberg MH, Kleinveld HA, Dekker FW, van Munster BC, Rabelink TJ, van Buren $\mathrm{M}$, et al. Functional and cognitive impairment, frailty, and adverse health outcomes in older patients reaching ESRD-A systematic review. Clin J Am Soc Nephrol. 2016;11(9):1624-39.

43. Griva K, Stygall J, Hankins M, Davenport A, Harrison M, Newman SP. Cognitive impairment and 7-year mortality in dialysis patients. Am J Kidney Dis. 2010;56(4):693-703.

44. Go AS, Chertow GM, Fan D, McCulloch CE, Hsu CY. Chronic kidney disease and the risks of death, cardiovascular events, and hospitalization. N Engl J Med. 2004:351(13):1296-305.

45. Ferreira L, Ferreira Santos-Galduroz R, Ferri CP, Fernandes Galduroz JC. Rate of cognitive decline in relation to sex after 60 years-of-age: a systematic review. Geriatr Gerontol Int. 2014;14(1):23-31.

46. Proust-Lima C, Amieva H, Letenneur L, Orgogozo JM, Jacamin-Gadda $\mathrm{H}_{\text {, }}$ Dartigues JF. Gender and education impact on brain aging: a general cognitive factor approach. Psychol Aging. 2008;23(3):608-20.

47. Deckers K, Camerino I, van Boxtel MP, Verhey FR, Irving K, Brayne C, et al. Dementia risk in renal dysfunction: a systematic review and meta-analysis of prospective studies. Neurology. 2017:88(2):198-208.

48. Mogi M, Horiuchi M. Clinical interaction between brain and kidney in small vessel disease. Cardiol Res Pract. 2011:2011:306189.

49. Berkhout-Byrne N, Kallenberg MH, Gaasbeek A, Rabelink TJ, Hammer S, van Buchem MA, et al. The cognitive decline in older patients with end stage renal disease (COPE) study - rationale and design. Curr Med Res Opin. 2017:33:1-8.

50. Wanner C, Inzucchi SE, Lachin JM, Fitchett D, von Eynatten M, Mattheus M, et al. Empagliflozin and progression of kidney disease in type 2 diabetes. $\mathrm{N}$ Engl J Med. 2016;375(4):323-34.

\section{Publisher's Note}

Springer Nature remains neutral with regard to jurisdictional claims in published maps and institutional affiliations. 